\title{
SEMANTIC ANALYSIS OVER LESSONS LEARNED CONTAINED IN SOCIAL NETWORKS FOR GENERATING ORGANIZATIONAL MEMORY IN CENTERS R\&D
}

\author{
Marco Javier Suárez Barón \\ $\mathrm{PhD}$ in Strategic and Technology Management, \\ UNITEC/FODESEP, Bogotá, Colombia \\ marcojaviersuarez @gmail. com
}

\begin{abstract}
This paper shows the construction of an organizational memory metamodel focused on $R \& D$ centers. The metamodel uses lessons learned extracted from corporative social networks; the metamodel aims to promote learning and management of organizational knowledge at these types of organizations. The analysis is applied initially from lessons learned on topics of $R \& D$ in Spanish language. The metamodel use natural languages processing together with ontologies for analyze the semantic and lexical the each lesson learned. The final result involves a knowledge base integrated by RDF files interrogated by SPARQL queries.
\end{abstract}

\section{KEYWORDS}

Knowledge management, Technological Innovation Management, Lessons Learned, Ontology, Metamodel

\section{INTRODUCTION}

In Colombia, and specifically in the capital Bogotá, the R\&D centers have become a key element in the scaffolding of science and technology [1]. R\&D centers are principally affiliated with universities and have been primarily conceived of as technology-based companies. According to the science and technology observatory [2], they are currently the source of human capital formation in terms of research and contribute to knowledge by solving problems with technology. For [3] knowledge generation and storage activities have become a necessity in the creation of competitive advantages in modern organizations. Under this light, this article proposes a model that determines the relevance of the knowledge and experience that circulate in these science and technology organizations as a key factor in establishing organizational learning strategies from lessons learned. The aim of this model is provide strategic elements to support organizational learning through lessons learned extracted from social networks; the model apply natural

Jan Zizka et al. (Eds) : CCSEIT, AIAP, DMDB, MoWiN, CoSIT, CRIS, SIGL, ICBB, CNSA-2016 pp. 257-267, 2016. @ CS \& IT-CSCP 2016

DOI : $10.5121 /$ csit.2016.60621 
language processing(NLP) and ontologies giving support to knowledge management in R\&D centers in Colombia.

\section{BACKGROUND}

Our literature review shows that innovation, development and research centers, known as $\mathrm{R}+\mathrm{D}$ centers, have had a key role at all levels in modern society, to promote and encourage creativity around the world. A variety of innovative and creative ideas are closely related to investigation projects that have provided a solution to current problems for humanity. These solutions respond to new technological necessities, through feasible, viable innovative and creativity methods [4]. First of all, creativity can be directed to the generation of new and useful ideas, whereas innovation is regarded as the process of transforming the best ideas into real products. [5], from New Delhi University, claim that creativity is an individual activity, whereas innovation is a team work. This study concludes that all innovation processes start with a necessity that leads to a creative idea.

Additionally, in $\mathrm{R}+\mathrm{D}$ centers, social capital has risen as a proper work frame to explain exchange mechanisms for organizational knowledge [6]. Lessons Learned, as well, are considered a type of knowledge for organizational learning which comes from experience, as it is claimed by [7]. In consequence, for knowledge transference to satisfy organization necessities, it is essential that lessons learned would be presented at the precise context and time in processes, so that they could be adapted to a learning process, as it was found by [8].

[9] Have stated that varied knowledge can move around from individual to individual. This research, carried out in collaboration with the Florida University in USA and the University of Bergen in Norway, shows that this knowledge reusing is not an easy task, but if it is extracted and retrieved in an efficient way, it could become a string strategy for organizational learning. Certainly, it is clear that the necessity to plan, test and measure new models directed to specific knowledge reusing and the supply of a latent space for this aim could be found in $\mathrm{R}+\mathrm{D}$ groups.

Finally, if it is possible to organize and articulate any type of knowledge stored in any organization or collective's repository, including those belonging to a research group, then that knowledge, originating from varied sources, could be integrated as part of a single source [10]. Integration is an important activity in knowledge reuse [11], because it makes easier to track different pieces of knowledge that might be retrieved later, enhancing in that way, the process of knowledge reuse.

\section{METHODOLOGY}

According to [12], organizational learning models lead to applying meta-learning usage comprising learning cycles, mentioned above. This meta-learning concept contributes directly to innovation, enhancing all organizational learning. In [13] is described how organizations could learn from their own innovation and development projects, as well as those adopted by other organizations.[14] states that models that are developed for organizational learning lack integration choices that could define permanent metamodels for organizational learning, especially those concerning technology surveillance issues in $\mathrm{R}+\mathrm{D}$ groups. That way, this knowledge might be shared, assembled and reused across a variety of organizational levels in a consistent way, using methods such as data ontologies [15]. 
This investigation has a mixed research approach including both qualitative and quantitative features, as a result of the usage of both approaches at different stages along the research process. Trends of $\mathrm{R}+\mathrm{D}$ issues in lessons learned were defined using a qualitative approach; they were determined through text structures contained in social networks with the aim of establishing a metamodel based on knowledge management and organizational learning for researchers in $\mathrm{R}+\mathrm{D}$ groups. On the other hand, determining statistical studies about behavioral background in relevant issues for $\mathrm{R}+\mathrm{D}$ was made using a quantitative approach. It was focused on providing support to $\mathrm{R}+\mathrm{D}$ groups in their decision taking and planning processes. This investigation has a correlational scope, since it was directed towards examining and analyzing technological and social variables behavior.

When improvement opportunities are considered, this type of model provides planning tools, since it makes possible to generate diagnosis using the information stored in social networks and its integration to other sources, such as documents and repositories, as it is stated by [16]. Also, it is possible to design strategies that could address $\mathrm{R}+\mathrm{D}$ data for forecasts fulfillment. Finally, according [17] an organization might be analyzed and cleansed through the use of information ontologies, so that it could be structured as learning metamodel, becoming a valuable tool for organizational planning and learning.

The chart displayed in Figure 1 shows the framework for integration of Metamodel with organizational learning architecture. Here the lessons learned in the top layer, are supported by tacit and explicit knowledge sources that circulate into corporate social networks. That knowledge collects information originating from workplace issues and people, respectively. They, in turn, receive information from the archive database and provide, simultaneously, data for integration to the organizational memory.

Within this proposed framework, we can see the application of the basic concepts for facilitating personal knowledge management (which in this article we have called "lessons learned"), integrated with the corporate social networks of each research center (tacit knowledge $\rightarrow>$ explicit knowledge). Therefore, profiling each person or group of people is imperative for the creation of knowledge. A computer application is developed to perform this task. It allows the extraction of information in real time from lessons learned, in ranges or time periods defined by the research community. Also the framework allows us to standardize concepts, practices, and criteria in order to apply the proposed metamodel, and it will serve as a reference to confront and solve new problems of a similar nature.Additionally, the framework aims to promote new ways of capturing knowledge, using sources such as lessons learned that circulate in social networks.

The model uses an organizational learning structure for knowledge management. It can also be observed in Figure 1, the model includes an analysis of six shared knowledge sources: people, processes, documents, issues and, tacit and explicit knowledge. In the same way, this model extracts from an ontology, denominated here as $\mathrm{R}+\mathrm{D}$ ontology, vocabulary from the $\mathrm{R}+\mathrm{D}$ field, its interrelations, concepts, and metadata, applied to the integration of retrieved knowledge. Natural Language Processing (NLP) techniques are used for metadata, so that they could be used in a correlational technique analysis. Finally, it can be observed the flow and relations existent between the organizational elements or entities that are part of the metamodel; in other words, the data-information-knowledge progression. 


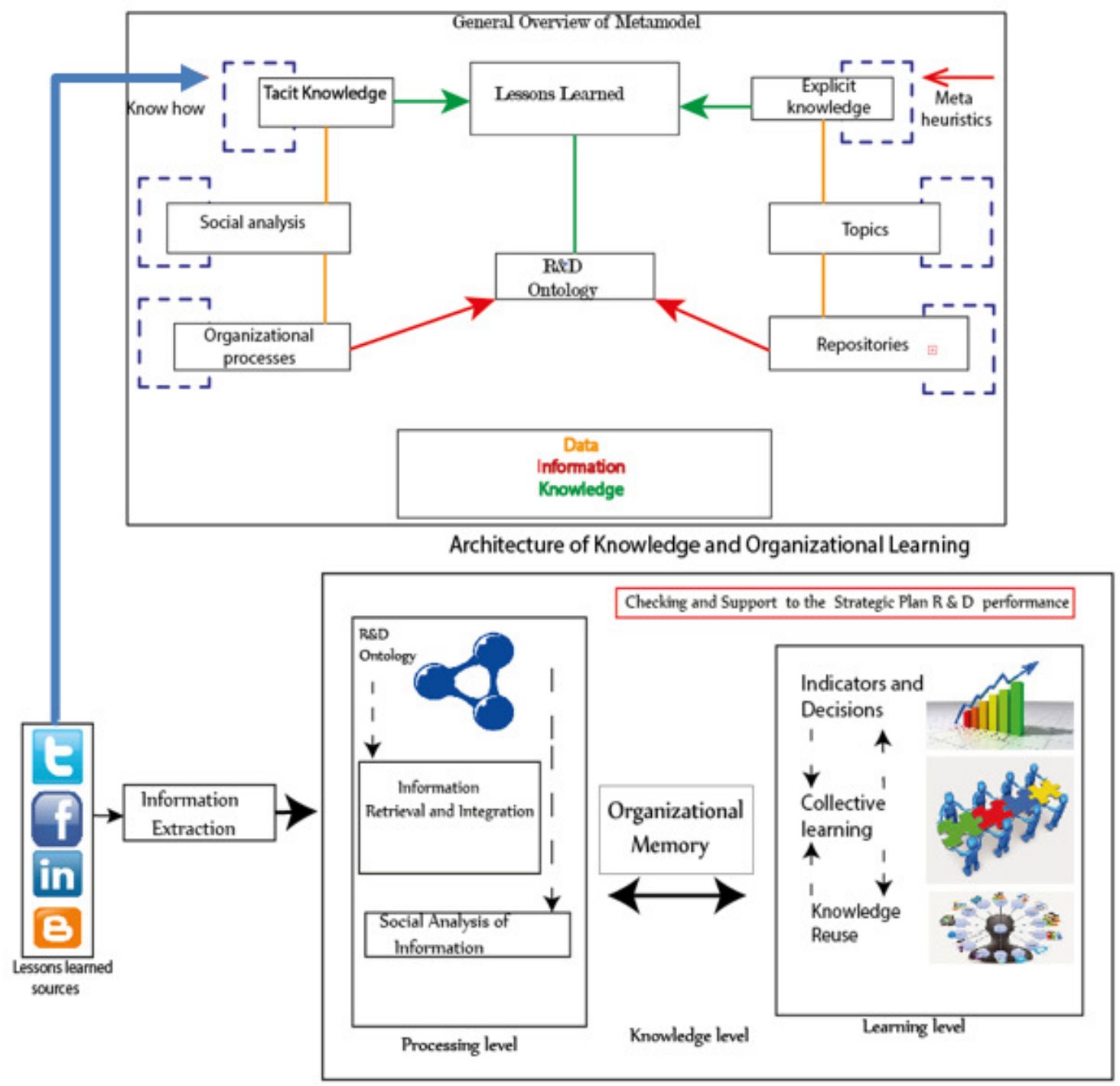

Figure 1: Global Architecture for the Knowledge Management Model

\section{RESULTS AND DISCUSSION}

$\mathrm{R}+\mathrm{D}$ ontology is a functional component in our framework; it provides a semantic solution because it defines the linguistic and hierarchic relations among specialized concepts and characteristics in the $\mathrm{R}+\mathrm{D}$ field, which are based on terminology from strategic planning on $\mathrm{R}+\mathrm{D}$. It also provides essential metadata for a declaratory representation of knowledge that can be communicated among people, processes and technology. Finally, it provides a formal definition for concepts that are agreed on, ensuring the correct interpretation of shared knowledge and providing a well-defined common vocabulary for information and knowledge exchange purposes in this field.

The METHONTOLOGY methodology was used for developing $\mathrm{R}+\mathrm{D}$ ontology. As it was stated by [18] this method provides guidelines to specify ontologies at a certain knowledge level, specifically providing techniques to determine conceptualization. The OWL ontology 
programming language was also used for designing and building $\mathrm{R}+\mathrm{D}$ ontology; it was executed under the Protégé 4.3 platform. As it can be seen in Figure 2, the categories diagram design was elaborated taking into account four main entities,: Thing, R+D, Innovation and, Development and Innovation; these categories are merged to generate the complete structure of the ontology.

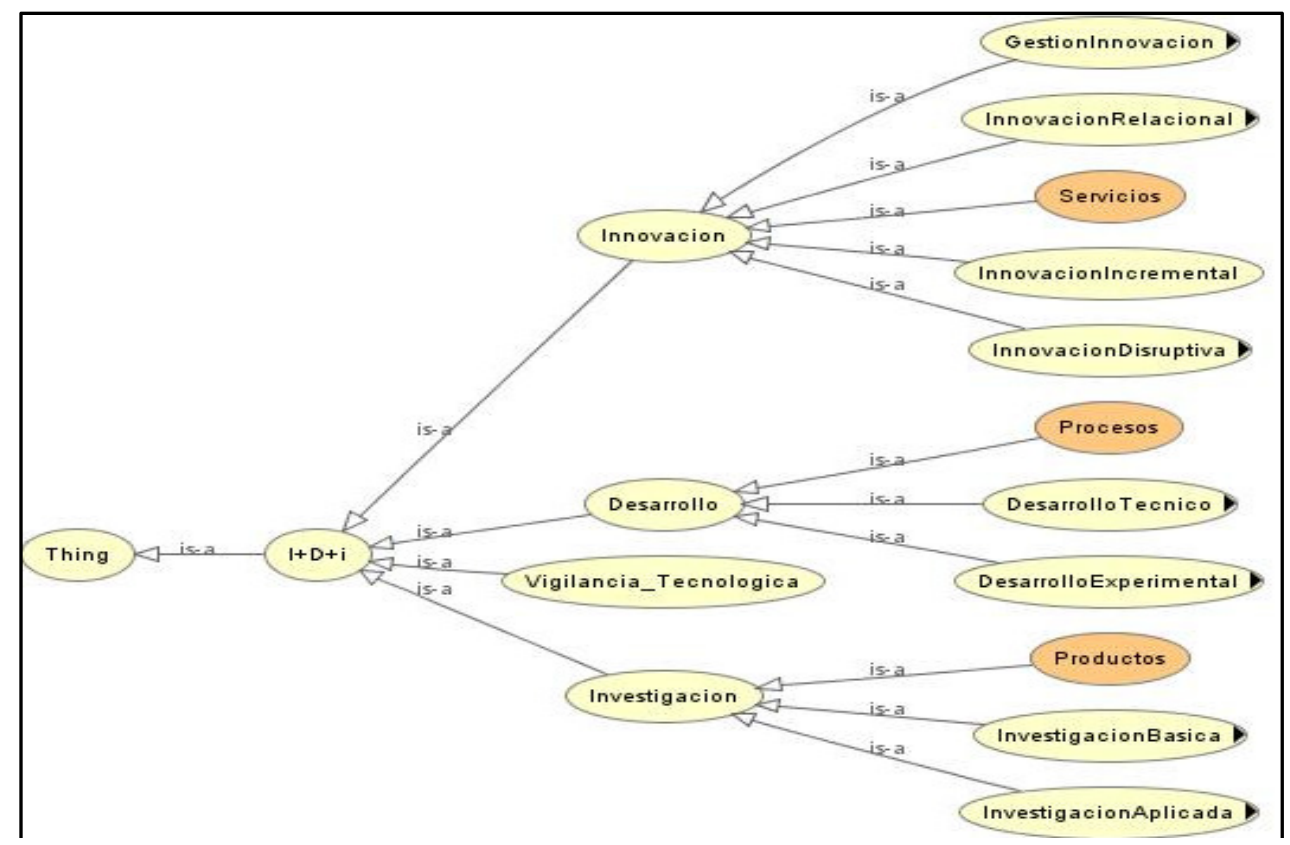

Figure 2. Partial View of Ontology R\&D

Organizational learning allows for understanding the impact that perceptions and opinions; shared by $\mathrm{R}+\mathrm{D}$ group human resources, have in a series of experiences or pieces of knowledge, for instance, technological surveillance. An $\mathrm{R}+\mathrm{D}$ group can perform regular offline analysis, writing reports using Organizational Memory data analysis (OM), retrieved and formalized in real time. This model makes easier to incorporate the great volume of spontaneous and real time information provided by social networks, forums and blogs to assess its impact on trends and thematic behavior, so that both critical events and competitive advantages could be discovered.

Each learning level receives all content packages at intervals (e.g. daily, weekly) and analyzes them to determine what is mentioned in the $\mathrm{R}+\mathrm{D}$ group social networks related to social and technological variables (e.g. positive, negative, neutral feelings) about issues such as technological surveillance.

The correlational analysis, once finished, is combined with statistical methods, such as factor analysis, both of which could be used to get merged trends in each lesson learned. Lessons learned are regarded as named entities, defined categories and, relevant and irrelevant topics in an $\mathrm{R}+\mathrm{D}$ group; those results might be eventually used to calculate aggregates, identify trends and, to write reports, dashboards, and performance measurements.

On the other hand, social networks such as Facebook, LinkedIn and Twitter become a potential source of information. Their generalized use is spread worldwide, and they generate a huge amount of information related to $\mathrm{R}+\mathrm{D}$ groups, which is useful as a supply for the knowledge 
management model. The structure and organization of lessons learned, regarded as "discoveries" in the model, represent the relations between the results of a process, a project, an indicator, a condition or a cause which have eased and/or blocked the $\mathrm{R}+\mathrm{D}$ groups strategic planning. Generally, it is recommended to describe such a discovery as a past event, even though it could be represented in the present whenever its effects and/or contexts keep being valid.

The knowledge management model continues with the implementation of a syntactical / morphological process of analysis, using the ontology-lexicon variation method, proposed by Mari (2009), which has been combined with NTKL (Natural Tool Kit Language), a natural language processing tool. When using NLTK, it was possible to separate each extracted lesson learned. The tree grammar decomposition described in Figure 3 tries to show the semantic behavior for each word, each one regarded as an entity contained in the $\mathrm{R}+\mathrm{D}$ data ontology; articles, connectors and linking words have been discarded in this analysis, since they are not part of the terminology ensemble considered in the Ontology.

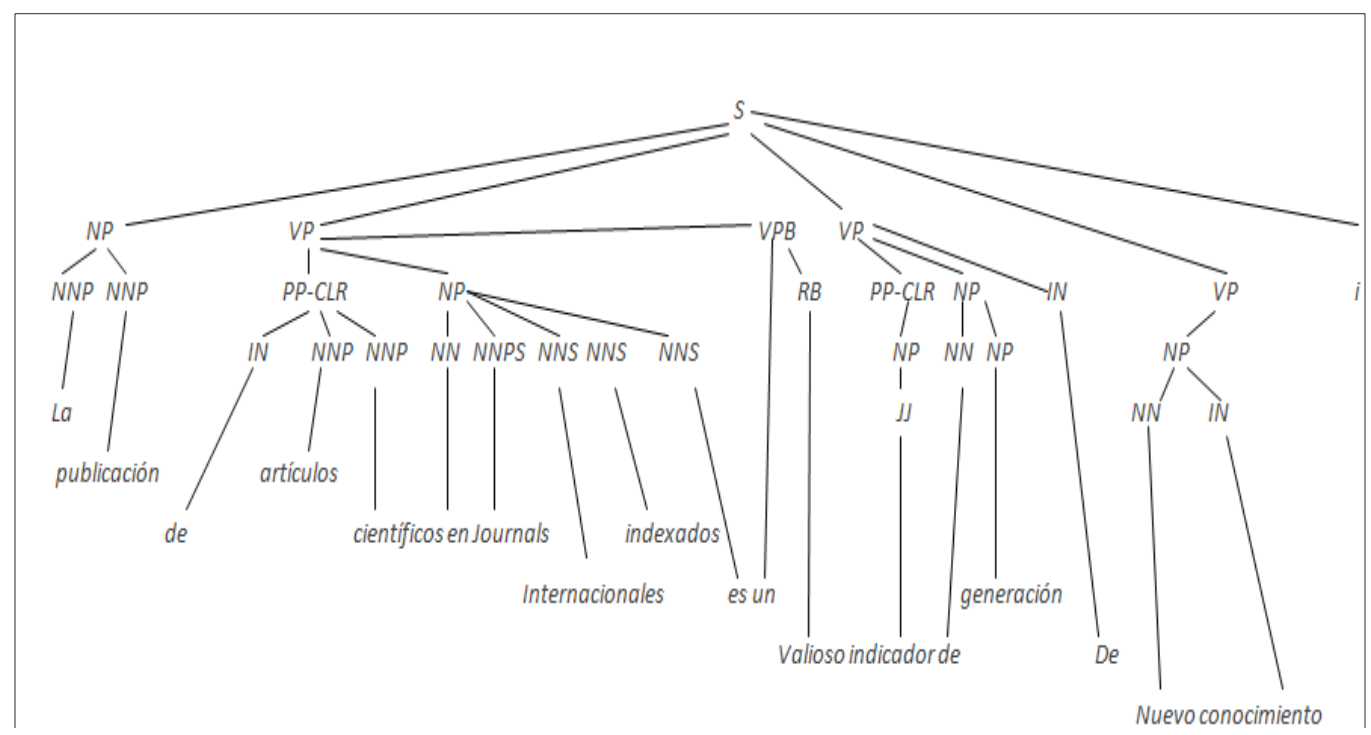

Figure 3. Lexical/morphological decomposition of a lesson learned taken from a social network In the syntactic/morphologic process of lessons learned, Spanish language grammar rules are applied, and it considers punctuation marks as key syntactic items, so that the reading of each one of the characters contained in texts related to lessons learned could be started/stopped. If each character $(c)$ in a phrase is considered as a chain, and spaces separate each character chain are followed additionally, by a period and a space, then that phrase is considered as complying with the suggested structure.

$$
P(c 1 c 2 c 3 . . c n)=\prod_{i=1}^{t} P(c i \mid c 1 \ldots c i-1)
$$

Eventually, the tokenization process is observed in Figure 3, applied to a lesson learned: " $L a$ publicación de artículos científicos en Journals internacionales indexados es un valioso indicador de generación de nuevo conocimiento" ["Scientific articles publication in international journals is a valuable sign of new knowledge generation]. Now, after applying the tokenization process, it is necessary to provide meaning to the phrase; this semantic analysis scenario in each 
lesson learned will be referred to as semantic tagging or noting. Figure 4 shows the semantic analysis through eagles tags, applied to the notation process in others lessons learned.

The noting or tagging process provides semantic content to the phrase; and it is based on the structure given in the syntactic/morphologic analysis. In other words, the subcategorization of items such as subject, verb, and predicates is attained at this stage, so that verbal arguments and their corresponding syntactic/semantic functions are identified; for example, the term "la producción científica" [the scientific production] could be considered as an instance of a nominative syntagma (Subject), but also, it could be read as a Nominative Predicate, based on our lexical structure.

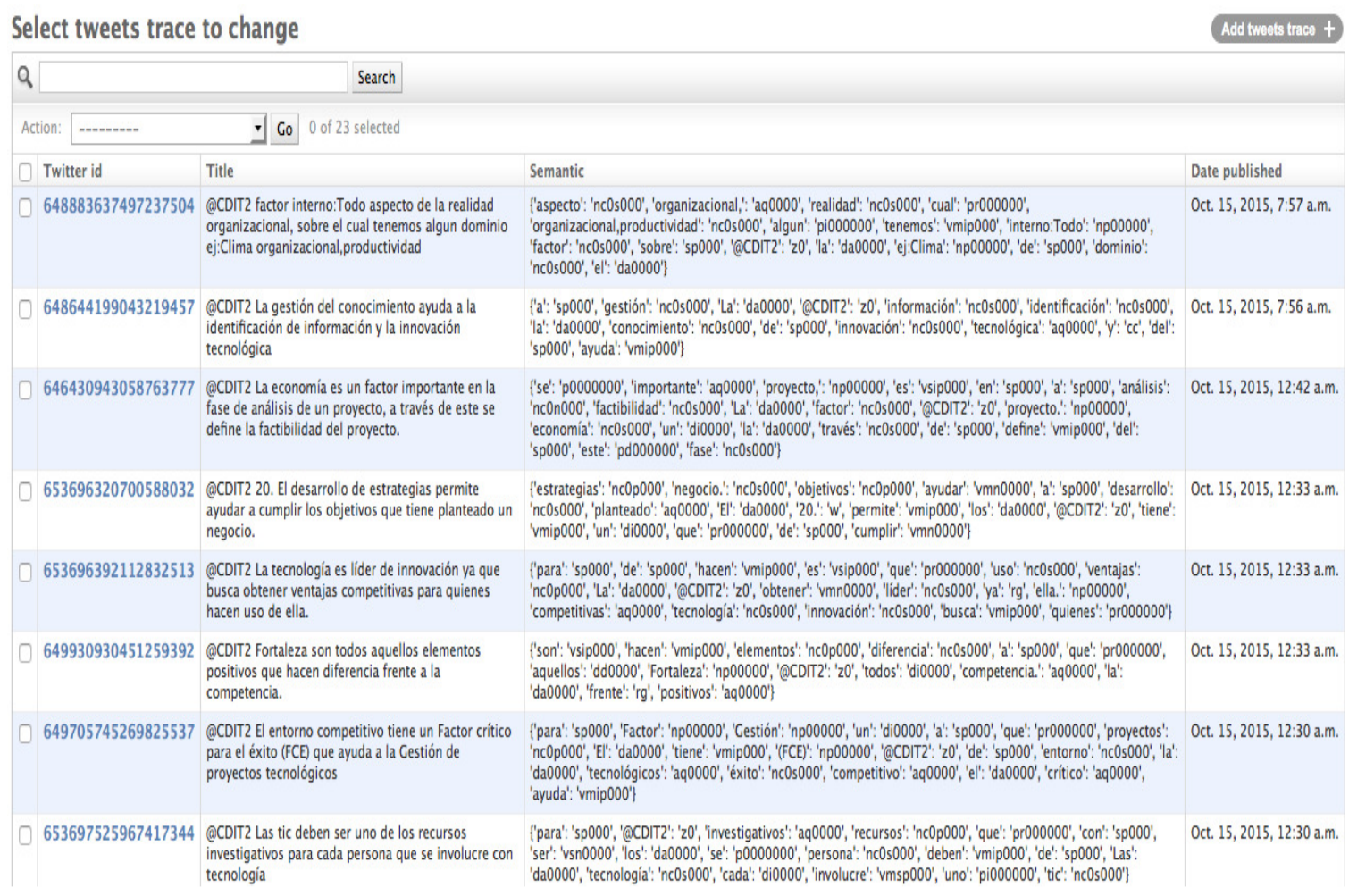

Figure 4. Lesson Learned Tokenization and Eagle Tagging application

We use SPARQL for recovery and querying of these scenarios in organizational memory; given that data structure is organized by RDF syntax. SPARQL queries apply the method of a priori association rules specified by (Lin, He, \& Everson, 2011); the association rules are given by the relation subject $(\mathrm{S})$, verb $(\mathrm{V})$, object $(\mathrm{O})$ according to:

$$
(\mathrm{S}, \mathrm{V}, \mathrm{O})
$$

The querying and interrogation to organizational memory aims to identify trends, issues, and feelings among others topics in corporate social networks that refer to themes of $\mathrm{R} \& \mathrm{D}$. The process relies on time ranges intervals where desired interrogate organizational memory. An example of this can be: from September 1, 2015 to September 3, 2015 (01/09 / 2015 03 / 09/2015). In addition, this research integrates the relationship of four axis of consulting the 
organizational memory; these axis are common strategic priorities in each of the development plans R \& D research centers analyzed; each axis correspond to the following strategic areas: scientific and technological areas, indicators R \& D (KPI), management projects and final results research R\&D. Additionally, in the process of querying the organizational memory it arises retrieve information about:

- Actions: events associated with entities and people, represented on verbs

- Entities: the basic text units; i.e. places,

- Subject: represents people, objects, proper names and other lexical features that could be grouped under the subject, etc.

- Concepts: entities concepts, this element might be contained in predicates.

- Relations established among entities.

- Events where entities are involved.

- Feelings.

Table 1 shows two query scenarios for two lessons learned semantically different. The first scenario is related to the strategic axis "scientific and technological areas"; the results shows that the semantic querying on the subject related ICT has relationship with scientific and technological area of the lesson learned; also it determined that the category to which reference is made corresponds to knowledge.

The other hand, the next scenario the lesson learned is related with research results R\&D; the querying want determine which are the subject (resources), verb(action) and object( description). The result shows that semantically these elements correspond to "patente", "realizar", and "invento".

Table 1. Scenarios for querying and retrieval information from Organizational Memory

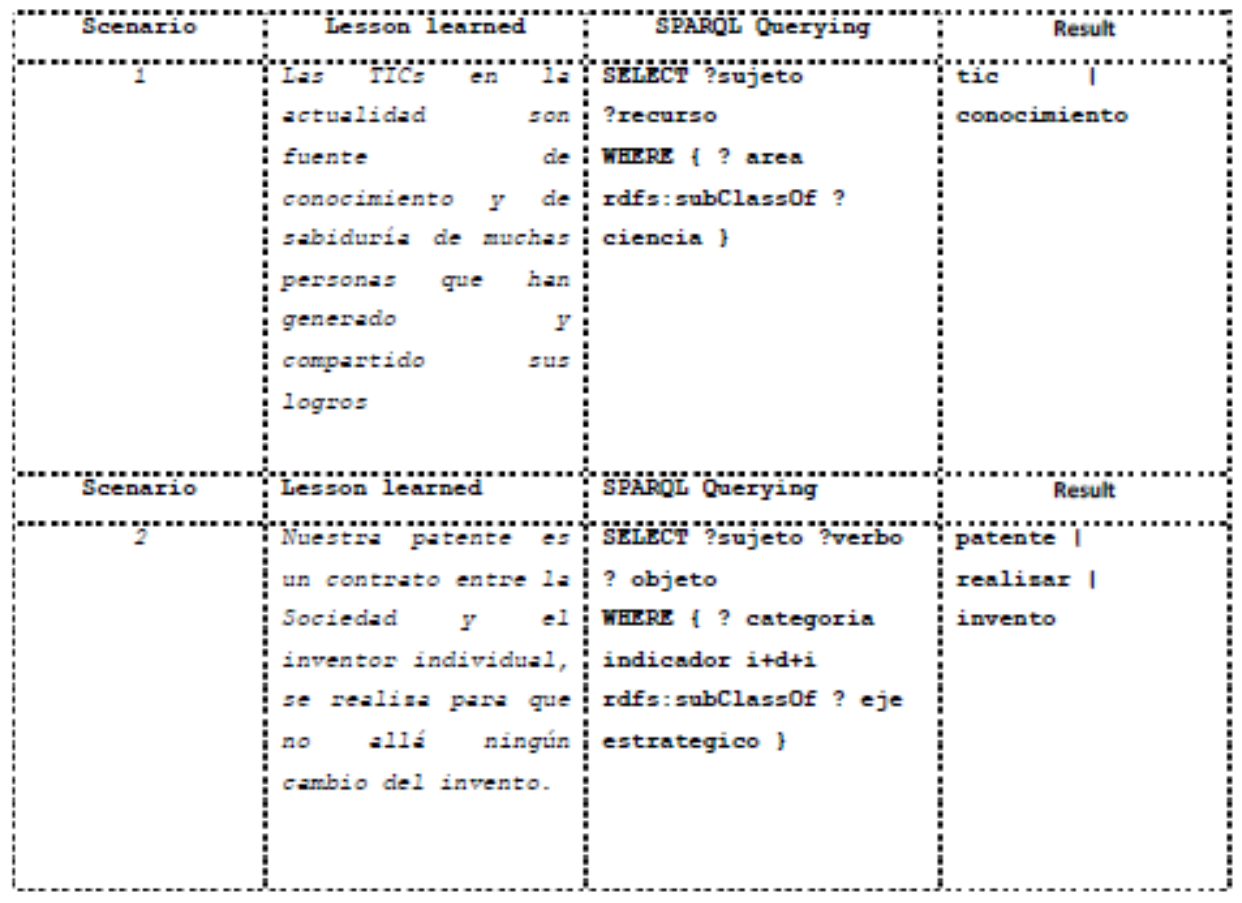




\section{CONCLUSIONS AND FUTURE WORK}

Reviewing the literature reveals that the lessons learned, in any type of project, allow a team or working group to investigate how their dynamic capabilities for managing knowledge are being generated, and what the profile being developed is. This is done via a systematic analysis of individual or personal profiles of each of its members on a timeline. As some authors referenced in this paper conclude, future studies should focus on developing adequate and comprehensive work environments, where each person or individual can share knowledge and be provided with easier knowledge flows. This would allow for the transformation of tacit knowledge into explicit knowledge, and also for working with learning and development objectives in the contexts or fields being developed at an R\&D center.

As many of the referred authors have concluded, the next step is providing proper and comprehensive spaces where every person and individual could share their knowledge, and, facilitating the flow of that knowledge. This will enhance the capacity of transforming tacit knowledge into explicit knowledge, which will allow for collaboration on learning objectives and development in contexts and areas where knowledge is generated in a research group.

In the same way, an organizational learning model design and validation is suggested, which will take into account lessons learned as a source of information, specifically, those circulating in corporate social networks related to $\mathrm{R}+\mathrm{D}$ groups. The establishment of a uniform text structure is foreseen for all lessons learned about issues such as technological surveillance. Additionally, it is essential to organize a data ontology that allows for a semantic analysis of each lesson learned to build a knowledge database at an organizational memory level. This model will become a useful support tool for research groups for strategic planning and decision taking. It is expected a closer work with research groups in accredited universities in Bogotá D.C., in order to validate these results. The quantity of people in charge of technology surveillance and management will be determined for each research group.

Finally, lessons learned organization should respond to a readable textual format in a natural language process where an analysis could be easily performed. The metamodel will use a logical sequence of data, information and knowledge for a real time analysis on each one of these three elements. These elements circulate across all entities in the model. A representative sample of institutional documents, such as forms and formats is taken, where they are considered important for knowledge capturing.

\section{ACKNOWLEDGEMENTS}

The author would like to thank to Colombian Fund for Development of Higher Education (Fondo para el Desarrollo de la Educacíon Superior-FODESEP)

\section{REFERENCES}

[1] Tanner, D, (2014), “Creativity and Innovation in R\&D”, R\&D Innovator, pp.101-150.

[2] OCyT, ocyt.org. Retrieved February 24, 2015, from http://ocyt.org.co/es-es/

[3] MinTics. Mintics.gov.co, Retrieved February 26 , 2015, from http:// Mintics.gov.co/ 
[4] Bisadi, M, (2012) "Future Research Centers: The place of creativity and innovation", Procedia Social and Behaviors Sciences, Vol. 12, pp. 232-243.

[5] Hamid, T. \& and Mehdi Jabbari Mohammed, (2011) "Product Innovation Performance in Organization", Procedia Technology, Vol. 1, pp. $521-523$.

[6] Wiing, K. (2007) "Integrating Intellectual Capital and Knowledge Management". Long Range Planning, pp. 399-405.

[7] Pirró, G., Mastroianni, C., \& Talia, D. (2010) "A framework for distributed knowledge management: Design and implementation". Future Generation Computer Systems, pp.38-49.

[8] Richter, P. \& R. Weber, (2013), Case-Based Reasoning, Springer, pp.53-84.

[9] Michael, S \& Davidsen, P. (2012)"How can organizational learning be modelled and measured?", Evaluation and Program Planning, Vol. 10, pp. 63-69.

[10] Bermell-Garcia P. Verhagen, W. \& Astwood, S., (2012) "A framework for management of Knowledge Based Engineering applications as software services: Enabling personalization and codification”. Advanced Engineering Informatics, Vol 20, pp. 219-230.

[11] Shehzad Rizwan \& Naeem Muhammed, (2013) "Integrating knowledge management with business intelligence processes for enhanced organizational learning", International Journal on Software Eng, Vol 5, pp. 83-92.

[12] Caeir, M., Llamas, M., \& Anido, L. (2014) "Computer Standards \& Interfaces". Computer Standards \& Interfaces, pp. 380-396.

[13] Greve, H. (2013), Microfoundations of Management: Behavioral Strategies and Levels of Rationality in Organizational Action. Academy of Management Perspectives, vol. 12, pp.103-119.

[14] Martinet, M, (2013) "L'intelligence economique. Les yeux et les oreilles de l'entreprise", París: Editions d'Organisation, Vol. 1, pp. 123-127.

[15] Corcho, O. (2010) "Construcción de ontologías legales con la metodología METHONTOLOGY y la herramienta WebODE". Law and the Semantic Web. Legal Ontologies, Methodologies, Legal, Information Retrieval, and Applications, Vol. 2, pp. 142-157.

[16] Ammann Eckhard, Ruiz-Montiel Marcela \& Navas-Delgado Ismael, (2010) "Knowledge Development Conception and its Implementation: Knowledge Ontology", Rule System, COGNITIVE, Vol 2, pp. 60-65.

[17] Makkonen Teemu \& Inkinen Tommi, (2013) "Innovation quality in knowledge cities: Empirical evidence of innovation award competitions in Finland", Expert Systems with Applications, Vol 2 pp. $5597-5604$.

[18] Gomez-Perez, J.M \& Corcho, O. (2008) "Problem-Solving Methods for Understanding Process Executions", Computing in Science \& Engineering, Vol. 10, no. 3, pp. 47-52.

[19] King, W. (2009) "Knowledge Management and Organizational Learning", Annals of Information System, Vol. 4, pp. 3-13. 


\section{AUTHOR}

\section{Marco Javier Suárez Barón}

$\mathrm{He}$ is Research at Unitec University from Bogota Colombia. He was borned in Duitama-Colombia; your works involves subject about machine learning, semantic web and knowledge discovery. Additionally the author received $\mathrm{PhD}$ in Strategic Planning and technology management at UPAEP México.

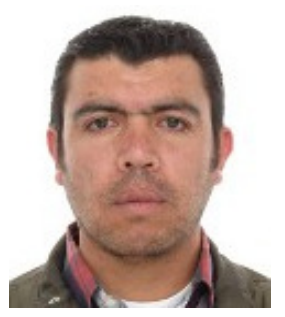

